\title{
ASSESSMENT OF SOCIODEMOGRAPHIC DETERMINANTS OF DEPRESSION AMONG PATIENTS ON HEMODIALYSIS.
}

1. MBBS, FCPS

Assistant Professor \& HOD

Psychiatry

DHQ, D.G. Khan Medical College, D.G. Khan.

2. MBBS, DPM, FCPS

Associate Professor \& Chairperson Psychiatry

Nishtar Medical University, Multan.

3. MBBS, MPH,

FCPS (Community Medicine) Assistant Prof

Quaid-e-Azam Medical College, Bahawalpur.

4. MBBS, FCPS

Assistant Professor Psychiatry Nishtar Medical University, Multan.

5. M.Sc, ADCP, M.Phil

Senior Clinical Psychologist

Nishtar Hospital, Multan.

6. MBBS, FCPS

Consultant Psychiatrist

PAF Hospital, Lahore.

Correspondence Address:

Dr. Naeem Ullah Leghari

Department of Psychiatry

Nishtar Medical University, Multan.

naleghari@live.com

Article received on:

17/09/2019

Accepted for publication:

$18 / 11 / 2019$
Hafiz Shafique Ahmad', Naeem Ullah Leghari², Wajahat Hussain ${ }^{3}$, Owais Kareem ${ }^{4}$, Bushra Akram ${ }^{5}$, Rabia Asghar ${ }^{6}$

ABSTRACT... Objectives: Study aimed to assess the frequency of depression in patients on hemodialysis and to see the effect of sociodemographic variables on depression. Study Design: Cross Sectional study. Setting: Hemodialysis unit of Nishtar Medical University, Multan. Period: July 2018 to December 2018. Material \& Methods: After taking ethical approval from Institutional ethical review committee. Total 384 patients with chronic kidney disease between the age range 16-60 years of both genders were included in the study. Patients of mood, psychotic and anxiety disorders before the onset of chronic kidney disease, other chronic disease and any substance abuse were excluded on the basis of history. The demographic data i.e. name, age, sex, locality, education \& socioeconomic status and employment status was collected from each patient. In addition to these, duration and frequency of dialysis was also noted. All patients were evaluated by single psychiatrist, using ICD-10 criteria for depression (yes / no). Results: Mean age of the respondents was $49.28 \pm 9.64$ years in our study. Out of the 384 patients, $235(61.2 \%)$ were male and 149 (38.80\%) were females Majority of patients $68.5 \%$ belonged to rural area, $86 \%$ had monthly family income less than $50,000,21.6 \%$ were unable to read \& write and $43.0 \%$ were unemployed. Depression was diagnosed in 175 (45.6\%) participants and there were 209 (54.4\%) patients having no depression. Age $(p<0.001)$, gender $(p<0.001)$, educational level $(p<0.001)$, employment status $(p<0.001)$, and monthly family income was significantly associated with depression in patients on hemodialysis. Conclusion: Study concluded that frequency of depression among patients on hemodialysis was very high and strong association observed between depression and extremes of ages, unemployment, education and poor socioeconomic status.

Key words: $\quad$ Chronic Kidney Disease, Depression, Quality of Life.

Article Citation: Ahmad HS, Leghari N, Hussain W, Kareem O, Akram B, Asghar R. Assessment of sociodemographic determinants of depression among patients on hemodialysis. Professional Med J 2020; 27(4):836-841. DOI: 10.29309/TPMJ/2020.27.04.4178

\section{INTRODUCTION}

With the demographic transition the geriatric population is increased in developed as well as developing societies which resulted in higher incidence and duration of chronic ailments. Additionally, the advancement in therapies and medical ethics relevant to chronic disease the issues now a days are beyond the concept of cure rather developed the concept of dignified quality of life. ${ }^{1,2}$ An increase interest in quality of life is observed in patients who suffer from chronic disease. ${ }^{3}$ Hemodialysis is mechanism that removes the waste products like urea, creatinine and free water from the blood when the patients are suffering from renal failure. The lives of patients are affected both physically and psychologically by the Hemodialysis. ${ }^{4}$ Depression is among leading psychiatric problems of chronic renal disease patients. Depression symptoms have gained the increased interest as measure of psychopathology among people with chronic kidney diseases. The influence on circle of relatives, work competency, death fear and treatment dependency may also have negative affect on quality of life and enhance the feelings related to loss of control. About $37 \%$ patients with chronic renal disease are suffering from depression because patients have to adopt themselves to a chronic physical illness and dependence on dialysis machine to stay alive. Depression is disease that results in low mood and loss of interest in day to day activities that may also 
affect a person's thoughts, actions, emotions and well-being. ${ }^{5,6,7}$ Persons suffering from depression may also experience low mood, look anxious, empty minded, hopelessness, worried, helpless, guilty, alone, irritable, hurt, or restless. Loss of interest in activities that were pleasing in the past, either have loss of appetite or overeating, have issues of concentration, unable to remember information or power of decision making is lost, and can ponder, try or commit suicide. Lack of sleep, excessive sleep, tiredness, body aches \& pains, problems of digestive system or decreased power may also be present. ${ }^{6}$ Recognition and managements of these troubles is of essential significance to enhance the quality of life in such sufferers. ${ }^{8,9}$ Data from community based studies in Pakistan display an alarming excessive burden of persistent renal diseases and about $15-20 \%$ of individuals up to forty years of age or older have a decreased glomerular filtration rate. ${ }^{10}$ The burden of depression among patients on hemodialysis is reported to be $48.8 \% .{ }^{11}$ Despite these facts, still depression is also remain unidentified and undertreated, especially among patients with ESRD. ${ }^{11}$ A systematic evaluation of the diseases in hemodialysis patients would provide facts about patients' feelings of wellbeing. Available literature suggest that screening for depression may additionally assist to patients at increased risk for death and hospitalization. Depression reduces patients' quality of life (QoL) and can progress to suicide or termination of hemodialysis if unrecognized or untreated. Patients often deny being depressed, because they don't want to be stigmatized. Dialysis patients frequently exhibit a depressive affect, which contribute to marital, family and occupational problems. ${ }^{12}$

The nephrology literature revealed the importance of depression management is the center of focus. Screening of the patients and provision of appropriate treatment has been recommended. However, majority of undiagnosed and untreated dialysis patients with depression shows the presence of barriers to utilize optimal mental health care. High self-esteem and less frequent mood disturbances are noted among patients with chronic renal disease if their quality of life is improved. This study aimed to assess the frequency of depression among hemodialysis patients in our local population. The findings of study would ultimately help the clinicians to design a proper protocol for evaluation of mental health of patients which are on hemodialysis, so proper counseling and treatment of these patients may be done for improving their life quality and reduction in the morbidity.

The main objective was to assess the frequency of depression among patients on hemodialysis and to see the effect of sociodemographic variables on depression at hemodialysis unit of Nishtar Medical University, Multan.

\section{MATERIALS \& METHODS}

This Cross Sectional descriptive study was conducted at Hemodialysis unit of Nishtar Medical University, Multan from July 2018 to December 2018 after obtaining ethical approval from ethical review committee of institute.

Sample size of 384 was calculated at confidence level of $95 \%$, margin of error $5 \%$ and anticipated population proportion of $48.8 \% .^{10}$ The patients of either gender with chronic kidney diseases between 16-60 years of age who were on hemodialysis for six months or more were taken in the study through non-probability, Consecutive method.

Patients of mood, psychotic and anxiety disorders before the onset of chronic kidney disease, other chronic diseases like chronic liver disease, diabetes mellitus, metabolic disorder, hepatitis B \& C, tuberculosis, myocardial infarction, congestive heart failure, hypothyroidism, stroke and any substance abuse were excluded on the basis of history.

Data was collected by using preformed pretested questionnaire which contained two parts. Part 1st included the patient's bio-data while part $2^{\text {nd }}$ contained the study variables. The demographic information like name, age, sex, locality, education \& socioeconomic status and employment status was noted in each patient. In addition to these, duration and frequency of dialysis was also noted. All patients were assessed by single psychiatrist, 
using ICD-10 criteria for depression (yes / no). Data was entered and analyzed through SPSS version 23.0. Quantitative variable like age was presented as mean and standard deviation. Qualitative variables like gender and depression (present/absent) were presented as frequency and percentages. Stratification was done according to age, gender, locality, education, socioeconomic status, employment status, duration of dialysis and frequency of dialysis. Post stratification chi-square test was applied to see the effect of these on depression (yes/no). P value $<0.05$ was considered as significant.

\section{RESULTS}

Mean age of the patients was $49.28 \pm 9.64$ years. Major proportion of the patients 187 (48.70\%) were between 46 to 60 years of age. Out of the 384 patients, 235 (61.20\%) were male and $149(38.80 \%)$ were females. Majority of the respondents (68.5\%) were from rural areas. Educational status of study participants showed that $21.6 \%$ were unable to even read and write, $37.5 \%$ had primary education and only $14.3 \%$ had above secondary level of education. Monthly family income of $86.5 \%$ respondents was below 50,000 and $43.0 \%$ respondents were employed. Depression was found in 175 (45.6\%) patients, whereas there were 209 (54.4\%) patients having no depression. When Stratification was done on age groups and gender, it was found $61.7 \%$ patients with age range of $46-60$ years had depression and there was significant difference of depression between different age groups $(p<0.001)$, whereas out of 175 patients with depression $73.1 \%$ were male and significant difference among genders was noted $(p<0.001)$. Education level $(<0.001)$, employment status $(P<0.001)$ and monthly family income (0.001) had statistically significant relationship with depression among patients on hemodialysis. No statistically significant difference of depression was noted among patients having more frequent dialysis as compared to their counterpart $(p=0.60)$. Stratification of respondents on the basis of place of residence also showed no statistically significant difference of depression among rural group compared to urban $(p=0.083)$.

\begin{tabular}{|c|c|c|}
\hline Variable & Frequency & Percentage \\
\hline $\begin{array}{l}\text { Age } \\
16-30 \\
31-45 \\
46-60 \\
\text { Total }\end{array}$ & $\begin{array}{l}046 \\
151 \\
187 \\
384\end{array}$ & $\begin{array}{l}12.0 \% \\
39.3 \% \\
48.7 \% \\
100 \%\end{array}$ \\
\hline $\begin{array}{l}\text { Gender } \\
\text { Male } \\
\text { Female } \\
\text { Total }\end{array}$ & $\begin{array}{l}235 \\
149 \\
384\end{array}$ & $\begin{array}{c}61.2 \% \\
38.8 \% \\
100 \%\end{array}$ \\
\hline $\begin{array}{l}\text { Residence } \\
\text { Rural } \\
\text { Urban } \\
\text { Total }\end{array}$ & $\begin{array}{l}263 \\
121 \\
384\end{array}$ & $\begin{array}{c}68.5 \% \\
31.5 \% \\
100 \%\end{array}$ \\
\hline $\begin{array}{l}\text { Education } \\
\text { Unable to read \& write } \\
\text { Primary } \\
\text { Up to Secondary } \\
\text { Above Secondary } \\
\text { Total }\end{array}$ & $\begin{array}{l}083 \\
144 \\
102 \\
055 \\
384\end{array}$ & $\begin{array}{l}21.6 \% \\
37.5 \% \\
26.6 \% \\
14.3 \% \\
100 \%\end{array}$ \\
\hline $\begin{array}{l}\text { Monthly Income } \\
<50,000 \\
\geq 50,000 \\
\text { Total }\end{array}$ & $\begin{array}{l}332 \\
052 \\
384\end{array}$ & $\begin{array}{l}86.5 \% \\
13.5 \% \\
100 \%\end{array}$ \\
\hline $\begin{array}{l}\text { Employment Status } \\
\text { Unemployed } \\
\text { Employed } \\
\text { Total }\end{array}$ & $\begin{array}{l}165 \\
219 \\
384\end{array}$ & $\begin{array}{l}43.0 \% \\
57.0 \% \\
100 \%\end{array}$ \\
\hline $\begin{array}{r}\text { Table-I. Sociodem } \\
\text { resp }\end{array}$ & $\begin{array}{l}\text { hic charact } \\
\text { nts }(n=384)\end{array}$ & stics of the \\
\hline
\end{tabular}

\begin{tabular}{|l|c|c|}
\hline \multicolumn{1}{|c|}{ Depression } & Frequency & Percentage \\
\hline Present & 175 & $45.6 \%$ \\
\hline Absent & 209 & $54.4 \%$ \\
\hline Total & 384 & $100 \%$ \\
\hline Table-II. Frequency of depression among patients on \\
hemodialysis
\end{tabular}




\begin{tabular}{|c|c|c|c|}
\hline \multirow{3}{*}{$\begin{array}{l}\text { Sociodemographic Characteristics } \\
\text { Age of the respondents } \\
16-30 \\
31-45 \\
46-60\end{array}$} & \multicolumn{2}{|c|}{ Depression } & \multirow{2}{*}{ P-Value } \\
\hline & Yes & No & \\
\hline & $\begin{array}{l}27(15.4 \%) \\
40(22.9 \%) \\
108(61.7 \%)\end{array}$ & $\begin{array}{c}19(09.1 \%) \\
111(53.1 \%) \\
79(37.8 \%)\end{array}$ & $<0.001$ \\
\hline $\begin{array}{l}\text { Gender } \\
\text { Male } \\
\text { Female }\end{array}$ & $\begin{array}{c}128(73.1 \%) \\
47(26.9 \%)\end{array}$ & $\begin{array}{l}107(51.2 \%) \\
102(48.8 \%)\end{array}$ & $<0.001$ \\
\hline $\begin{array}{l}\text { Education } \\
\text { Unable to read \& write } \\
\text { Primary } \\
\text { Up to Secondary } \\
\text { Above Secondary }\end{array}$ & $\begin{array}{l}61(34.9 \%) \\
39(22.3 \%) \\
57(32.6 \%) \\
11(06.2 \%)\end{array}$ & $\begin{array}{c}22(10.5 \%) \\
105(50.2 \%) \\
45(21.5 \%) \\
37(17.8 \%)\end{array}$ & $<0.001$ \\
\hline $\begin{array}{l}\text { Residence } \\
\text { Rural } \\
\text { Urban }\end{array}$ & $\begin{array}{c}112(64.0 \%) \\
63(36.0 \%)\end{array}$ & $\begin{array}{c}151(72.2 \%) \\
58(27.8 \%)\end{array}$ & 0.083 \\
\hline $\begin{array}{l}\text { Frequency of dialysis } \\
<8 \text { times/ month } \\
>8 \text { times/month }\end{array}$ & $\begin{array}{c}65(37.1 \%) \\
110(62.9 \%)\end{array}$ & $\begin{array}{c}83(39.7 \%) \\
126(60.3 \%)\end{array}$ & 0.60 \\
\hline $\begin{array}{l}\text { Employment status } \\
\text { Unemployed } \\
\text { Employed }\end{array}$ & $\begin{array}{l}97(55.4 \%) \\
78(44.6 \%)\end{array}$ & $\begin{array}{c}68(32.5 \%) \\
141(67.5 \%)\end{array}$ & $<0.001$ \\
\hline $\begin{array}{l}\text { Monthly Income } \\
<50,000 \\
\geq 50,000\end{array}$ & $\begin{array}{c}162(92.6 \%) \\
13(07.4 \%)\end{array}$ & $\begin{array}{c}170(81.3 \%) \\
39(18.7 \%)\end{array}$ & 0.001 \\
\hline
\end{tabular}

Table-III. Sociodemographic characteristics of the respondents and depression

\section{DISCUSSION}

Depression serves the role of trigger in the progression of chronic ailments. People suffering from depression feels hopeless that their will to live is lost. As a result the patient fails to show compliance with the treatment and the situation become worse due to lack of interest in preventive measures. Lack of interest in food intake results in macro and micro nutrient deficiencies and the things become even more worse. Loss of physical fitness would also results in progression of depression and start of vicious cycle. Chronic renal ailment is also persistent problem and irrelevant to the cause of renal disease, fitness to perform the routine activities reduces with its progression till the end stage renal disease (ESRD). Total sample 385 with chronic renal failure which were on hemodialysis was included in the study. Mean age of the study participants was $49.28 \pm 9.64$ years. About half of the patients $187(48.70 \%)$ were between 46 to 60 years of age. Out of the 384 patients, almost two third (61.20\%) were male. Educational status of study participants revealed that one fourth of the patients were even unable to read and write.

Our study findings revealed that the frequency of depression among patients on hemodialysis was $45.6 \%$ which is lower than the findings of study by Hawamdeh $S$ et al. in which the $28 \%$ of the participants had mild depression, $26 \%$ moderate depression, $8 \%$ severe depression and $7 \%$ very severe. Thirty-one percent of the participants were found to be normal. This difference in frequency of depression may be due to the fact that Hawamdeh et al. assessed the patients through HAM-D tool and there is also difference in sociodemographic characteristics of the respondents. ${ }^{13}$

Our study findings revealed the statistically significant difference of depression between various age groups $(p<0.001)$, and genders $(p<0.001)$ Education level $(<0.001)$, employment status $(P<0.001)$ and monthly family income (0.001) had statistically significant relationship with depression among patients 
on hemodialysis. Monthly frequency of dialysis and place of residence was not significantly related with depression in our study $(p=0.60)$. Monthly family income of the respondents was significantly associate with depression in this study which is similar to the findings of Hawamdeh $S$ et al. in which low income was found to be significantly associated with depression. ${ }^{13}$ The review of literature revealed few studies have found an association between CKD and adverse psychosocial outcomes including quality of life poor social support, and sexual dysfunction in the local context of Pakistan. Patients with depression had significantly less integration into the community, less social support, and lower quality of life than patients without depression. ${ }^{14}$ More studies of the effects of mildto-moderate CKD on psychosocial outcomes in our local context are needed at this time.

\section{CONCLUSION \& RECOMMENDATIONS}

Our study findings conclude that patients of chronic renal failure and their attendants need to be educated on the high burden of problem and their determinants in the community. Social and psychological support of the patients with chronic renal diseases (CKD) and their caregiver should be an essential part of the management.

Copyright@ 18 Nov, 2019.

\section{REFERENCES}

1. Lee YJ, Kim MS, Cho S, Kim SR. Association of depression and anxiety with reduced quality of life in patients with predialysis chronic kidney disease. International journal of clinical practice. 2013 Apr; 67(4):363-8.

2. Zalai D, Szeifert L, Novak M. Psychological distress and depression in patients with chronic kidney disease. In Seminars in dialysis 2012 Jul (Vol. 25, No. 4, pp. 428-438). Oxford, UK: Blackwell Publishing Ltd.

3. Triposkiadis F, Giamouzis G, Parissis J, Starling RC, Boudoulas H, Skoularigis J, Butler J, Filippatos G. Reframing the association and significance of $\mathrm{co} \square$ morbidities in heart failure. European journal of heart failure. $2016 \mathrm{Jul} ;$ 18(7):744-58.

4. Loosman WL, Siegert CE, Korzec A, Honig A. Validity of the Hospital Anxiety and Depression Scale and the Beck Depression Inventory for use in end $\square$ stage renal disease patients. British Journal of Clinical Psychology. 2010 Nov; 49(4):507-16.
5. Rosenthal Asher D, Ver Halen N, Cukor D. Depression and nonadherence predict mortality in hemodialysis treated end $\square$ stage renal disease patients. Hemodialysis International. 2012 Jul; 16(3):387-93.

6. Taraz M, Taraz S, Dashti $\square$ Khavidaki S. Association between depression and inflammatory/anti inflammatory cytokines in chronic kidney disease and end $\square$ stage renal disease patients: $A$ review of literature. Hemodialysis International. 2015 Jan; 19(1):11-22.

7. Belayev LY, Mor MK, Sevick MA, Shields AM, Rollman BL, Palevsky PM, Arnold RM, Fine MJ, Weisbord SD. Longitudinal associations of depressive symptoms and pain with quality of life in patients receiving chronic hemodialysis. Hemodialysis International. 2015 Apr; 19(2):216-24.

8. Chen CK, Tsai YC, Hsu HJ, Wu IW, Sun CY, Chou CC, Lee CC, Tsai CR, Wu MS, Wang LJ. Depression and suicide risk in hemodialysis patients with chronic renal failure. Psychosomatics. 2010 Nov 1; 51(6):528.

9. Bossola M, Vulpio C, Tazza L. Fatigue in chronic dialysis patients. In Seminars in dialysis 2011 Sep (Vol. 24, No. 5, pp. 550-555). Oxford, UK: Blackwell Publishing Ltd.

10. Anees M, Hameed F, Mumtaz A, Ibrahim M, Khan MN. Dialysis-related factors affecting quality of life in patients on hemodialysis. Iranian journal of kidney diseases. 2011; 5(1):9.

11. Khan MA, Ahmad M. Anxiety, depression and cognitive changes in patients on hemodialysis. Pakistan Armed Forces Medical Journal. 2012 Jun 30; 62(2):288-92.

12. Keskin G, Engin E. The evaluation of depression, suicidal ideation and coping strategies in haemodialysis patients with renal failure. Journal of clinical nursing. 2011 Oct; 20(19๑20):2721-32.

13. Hawamdeh S, Almari AM, Almutairi AS, Dator WL. Determinants and prevalence of depression in patients with chronic renal disease, and their caregivers. International journal of nephrology and renovascular disease. 2017; 10:183.

14. Shirazian S, Grant CD, Aina O, Mattana J, Khorassani $\mathrm{F}$, Ricardo AC. Depression in chronic kidney disease and end-stage renal disease: Similarities and differences in diagnosis, epidemiology, and management. Kidney International Reports. 2017 Jan $1 ; 2(1): 94-107$. 


\begin{tabular}{|c|l|l|l|}
\hline \multicolumn{3}{|c|}{ AUTHORSHIP AND CONTRIBUTION DECLARATION } \\
\hline Sr. \# & \multicolumn{1}{|c|}{ Author(s) Full Name } & Contribution to the paper & Author(s) Signature \\
\hline 1 & Hafiz Shafique Ahmad & 1st Author \\
\hline 2 & Naeem Ullah Leghari & 2nd Author \\
\hline 3 & Wajahat Hussain & 3rd Author \\
\hline 5 & Oushra Akram & 4th Author \\
\hline 6 & Rabia Asghar & 5th Author & \\
\hline
\end{tabular}

